\title{
Anchorage-independent Colony Growth of Pulmonary Fibroblasts Derived from Fibrotic Human Lung Tissue
}

Diane J. Torry, Carl D. Richards, Thomas J. Podor, and Jack Gauldie

Department of Pathology, Molecular Virology and Immunology Program, McMaster University, Hamilton, Ontario, Canada L8N $3 Z 5$

\begin{abstract}
Fibroblast heterogeneity is known to exist in chronically inflamed tissue such as pulmonary fibrosis (IPF) and scleroderma. We have previously shown differences in proliferation rates in primary lines and cloned lines of fibroblasts derived from IPF tissue compared with normal lung. In this study, we report that cell lines derived from fibrotic tissue demonstrate anchorage-independent growth in soft agarose culture whereas normal lung fibroblast lines do not. We also show that fibroblast lines derived from neonatal lung tissue form colonies at about the same frequency as the fibrotic cells. Colonies from both fibrotic and neonatal lines were shown to be positive for vimentin, laminin, fibronectin, fibronectin receptor, $\beta$-actin, and tropomyosin by immunohistochemistry but were negative for desmin, keratin, Factor VIII, $\alpha$-smooth muscle cell actin, and tenascin. Treatment with cytokines TGF- $\beta$ and PDGF or with corticosteroid modified the colony-forming capacity of fibrotic and neonatal cell lines, however, none of these treatments induced normal lung cell lines to form colonies. The presence of cells in adult fibrotic tissue with growth characteristics similar to those exhibited by neonatal cells is further evidence of fibroblast heterogeneity and suggests newly differentiated fibroblasts may be prevalent in fibrotic tissue and contribute directly to the matrix disorder seen in this disease. (J. Clin. Invest. 1994. 93:1525-1532.) Key words: idiopathic pulmonary fibrosis • fibroblast heterogeneity • soft agarose growth • inflammation
\end{abstract}

\section{Introduction}

Pulmonary fibrosis is a chronic and devastating condition characterized by pathologic alterations of extracellular matrix elements ultimately affecting the functional integrity of the lung (1-6). Thought to be initiated by inflammatory reactions in the alveolar wall, fibrosis is most likely the end result of a dynamic repair cascade, which proceeds to chronicity by unknown mechanisms (7-9). In addition to well-recognized contributions made to the process by inflammatory cells, we and others have demonstrated that tissue structural cells, including fibroblasts, endothelial cells, and epithelial cells, are capable of releasing potent inflammatory and matrix modulating media-

Address correspondence to Dr. Jack Gauldie, Department of Pathology, 2N16, McMaster University, 1200 Main Street West, Hamilton, Ontario L8N 3Z5, Canada.

Received for publication 9 September 1993 and in revised form 22 December 1993.

J. Clin. Invest.

(C) The American Society for Clinical Investigation, Inc.

$0021-9738 / 94 / 04 / 1525 / 08 \quad \$ 2.00$

Volume 93, April 1994, 1525-1532 tors $(10,11)$ and hence play a direct role, as effectors, in the pathogenesis of idiopathic pulmonary fibrosis (IPF). ${ }^{1}$

The existence of phenotypic heterogeneity within the resident fibroblast population of a given tissue has been widely described. We and others have previously reported that fibroblast lines established from histologically proven fibrotic tissue or chronically altered dermal tissue display differences in proliferative potential, matrix gene expression, cell surface marker expression, and cell-mediated responses (12-16). Moreover, we have also shown similar proliferative differences with primary lines established from neonatal lung tissue (17). However, whether these in vitro differences relate directly to the fibrotic process or contribute to the chronic inflammatory reaction is not yet clear.

Recently, a number of cytokines have been shown to have a profound impact on fibroblast characteristics, including growth factors such as PDGF and TGF- $\beta$. These factors modulate fibroblast proliferation and can mediate transformation of fibroblasts, inducing these cells to anchorage-independent growth (reviewed in references 18 and 19). Moreover, TGF- $\beta$ and PDGF have been shown to be present in greatly enhanced amounts in lung biopsies from IPF patients (20-23), implying that cells found in IPF tissue may exhibit characteristics of growth consistent with chronic exposure to these cytokines.

To determine whether the various fibroblast lines we have established from adult and neonatal human lung tissue demonstrate abnormal growth characteristics, we established a soft agarose suspension culture assay and show here that primary fibroblast cell lines derived from human adult fibrotic lung tissue, but not those from normal adult lung tissue, form colonies under anchorage-independent growth conditions. Further, we show that primary fibroblast lines derived from neonatal lung tissue also exhibit the ability for colony formation under anchorage-independent conditions. These colonies demonstrate a pattern of synthesis of intra- and extracellular matrix (ECM) proteins typical of fibroblasts. Anchorage-independent growth characteristics are maintained by the fibrotic cells even after selection and clonal expansion of single colonies. The presence of these "transformed" phenotypes in fibrotic adult and neonatal cell lines suggests the process leading to fibrosis may involve de novo stromal cell differentiation, possibly under the influence of inflammatory mediators.

\section{Methods}

Reagents. Streptavidin-peroxidase immunohistological staining kit was purchased (Histostain-SP Kit 95-6543 for use with mouse primary antibody; 95-6143 for use with rabbit primary antibody; Zymed Labs.,

1. Abbreviations used in this paper: AcA, acetic acid alcohol; DEX, dexamethasone; ECM, extracellular matrix; EM, electron micrograph; IPF, ideopathic pulmonary fibrosis; LMP, low-melting point. 
Inc. San Francisco, CA). Hematoxylin solution Gill No. 2 was purchased (GHS-2-178; Sigma Chemical Co., St. Louis, MO). Agarose for use in the anchorage-independent growth assay was purchased (5510UB; Bethesda Research Laboratories, Gaithersburg, MD). All human sera used in growth assays were obtained from healthy normal volunteers using vacutainer sterile blood collection tubes with no additives (Becton Dickinson Canada Inc., Mississauga, Canada). Recombinant human PDGF was obtained (2038-01; Genzyme, Cambridge, MA). TGF- $\beta$ was obtained (100-B; R \& D Systems, Minneapolis, MN). Dexamethasone (DEX) was purchased (DIN 00664227; Sabex, Boucherville, Quebec, Canada).

Antibodies. Antisera to human antigens were purchased from Sigma Chemical Co.: $\alpha$-actin (A-2668, polyclonal); $\alpha$-tropomyosin (T3651, poly) $\alpha$-vimentin (V-6630, mAb); $\alpha$-SMC actin (A-9047, mAb); $\alpha$-laminin (L-6145, polyclonal); $\alpha$-desmin (D-9159, mAb); $\alpha$ cytokeratin (P-1548, mAb). Antisera to human antigens were purchased from Dako Corp. (Carpinteria, CA): $\alpha$-tenascin (M-636, mAb); $\alpha$-CD34 (M-824, mAb); $\alpha$-fibronectin (A-245, polyclonal); $\alpha$ Factor VIII (A-082, polyclonal); nonimmunized rabbit serum (X902). Purified mouse myeloma IgG1 was purchased from Zymed Labs., Inc. (02-6100). Antiserum to human fibronectin receptor was purchased from Telios Pharmaceuticals, Inc. (San Diego, CA) (A-108, polyclonal).

Cell lines. We have previously established a number of human primary fibroblast lines. Fibroblast lines were established by outgrowth from explants as previously described $(16,17)$. Three cell lines were established from tissues taken at open lung biopsy for diagnosis of interstitial lung disease and from areas shown histologically to demonstrate features of active fibrosis. Four lines were established from histologically normal adult lung tissue removed as part of resection of tumor mass, and two lines were established from normal neonatal lung tissue removed at autopsy within $12 \mathrm{~h}$ of death from premature infants dying within the first $3 \mathrm{~d}$ of life from causes not related to pulmonary function. Cell lines were used within the first five passages only. Lung fibroblast lines were grown in $75-\mathrm{cm}^{2}$ tissue culture flasks (Corning Inc., Corning, NY) and maintained in RPMI supplemented with $10 \%$ fetal bovine serum (Gibco Laboratories, Grand Island, NY) and $1 \%$ penicillin/streptomycin (Gibco Laboratories). The human fibrosarcoma cell line HT-1080 was obtained from American Type Culture Collection (Rockville, MD)(CCL 121). HT-1080 cells were maintained in MEM F-15 supplemented with $10 \%$ fetal bovine serum.

Anchorage-independent growth assay. An anchorage-independent growth assay similar to that previously described (24) was carried out in T-24 plates (Nunclon; InterMed Nunc, Roskilde, Denmark) with the following modifications. From a $2 \%$ stock agarose solution in PBS, a $0.8 \%$ agarose mixture was prepared and used to precoat 24-well plates. The agarose mixture was allowed to solidify at room temperature and the plates placed at $37^{\circ} \mathrm{C}$ until use. Subconfluent cultures of fibroblast cell lines (passage $<8$ ) were washed twice in warm PBS, trypsinized, centrifuged, and resuspended to a concentration of 800,000 cells $/ \mathrm{ml}$. Cell viability was $>95 \%$ at the start of the assay as assessed by trypan blue exclusion. The colony-forming assay was optimized by varying percentages of normal human serum. For all experiments presented, a $0.4 \%$ agarose mixture containing $20 \%$ AB human serum was prepared, cooled to $37^{\circ} \mathrm{C}$, and a fixed number of cells $(1.5$ $\times 10^{4}$ ) added to this mixture. The agarose/cell mixture was then layered over the base layer, allowed to solidify, and $100 \mu \mathrm{l}$ of media without FCS was added to each well in order to keep the cultures moist. The cultures were then incubated at $37^{\circ} \mathrm{C} / 5 \% \mathrm{CO}_{2}$ and the wells examined daily for colony growth. We observed optimal colony growth 10 $14 \mathrm{~d}$ after plating at which time colonies with a diameter $>45 \mu \mathrm{m}$ were scored. We chose $45 \mu \mathrm{m}$ to be representative of a colony, since in general, the size distribution of the colonies appearing in the agarose varied between 45 and $100 \mu \mathrm{m}$ and only occasionally were there smaller clusters of cells within the agarose layer. A single-cell suspension was ensured (and confirmed by light microscopy) at the start of the assay by repeated passage of the cells through a 25 -gauge needle. An inverted light microscope fitted with an eyepiece with a grid (Carl
Zeiss, Inc., Thornwood, NY) was used to calculate the diameter of the colonies and to count total colonies in a well. Agarose blocks containing the cell colonies were harvested, fixed in acetic acid alcohol (AcA) for $24 \mathrm{~h}$, paraffin embedded, and 4- $\mu \mathrm{m}$ sections cut onto APTEX slides for use in immunohistochemical studies. Two controls were included. (a) Normal human lung fibroblasts were grown to confluency, washed twice with warm PBS, trypsinized, centrifuged, and a cell pellet was obtained. A 2:1 ratio ( $\mathrm{vol} / \mathrm{vol}$ ) of the agarose solution was added to the pellet and the mixture stirred to disperse the cells. The agarose/cell mixture was allowed to harden, fixed in AcA, and then processed as described above; $(b)$ Human fibrosarcoma line HT-1080 was used as a positive control for colony formation. The cells were treated similar to the fibrotic lines.

Colony expansion. To pick and expand individual cell colonies, the above assay was repeated using low-melting point (LMP) agarose (5517UA; Bethesda Research Laboratories, Gaithersburg, MD) (25). Briefly, a base layer containing 1\% LMP agarose was poured into each of 96 wells (Nunclon, InterMed Nunc, Roskilde, Denmark) and allowed to solidify at $4^{\circ} \mathrm{C}$. A fixed number of cells $\left(3 \times 10^{3}\right.$ cells $/$ well $)$ was then added to the top layer (0.3\% LMP agarose/20\% human serum) and this mixture layered over the base layer. The top layer was allowed to solidify at room temperature and then the plates were wrapped in aluminum foil to avoid drying out and placed at $37^{\circ} \mathrm{C} / 5 \%$ $\mathrm{CO}_{2}$. In 7-10 d, those colonies with a diameter $>45 \mu \mathrm{m}$ were removed from the agarose by use of a micropipette and inverted microscope and expanded in culture in RPMI supplemented with 10\% FBS and 1\% pen/strep.

Immunostaining of colonies. Immunoperoxidase staining of colonies was performed according to the manufacturer's instructions (Zymed Labs., Inc.) with minor modifications. Paraffin sections were dewaxed in xylene, passed through an ethanol series, and blocked for endogenous peroxidase activity with $\mathrm{H}_{2} \mathrm{O}_{2}$-methanol- $\mathrm{HCl}$ solution for $30 \mathrm{~min}$ at room temperature. Slides were then rinsed in $70 \%$ ethanol followed by distilled water, and then washed in Tris-buffered saline, $\mathrm{pH}$ 7.6 (TBS buffer). After incubation with nonimmune serum to block nonspecific binding, primary antibodies were applied to the sections and allowed to bind at room temperature for $1 \mathrm{~h}$. The sections were then rinsed in TBS buffer, overlaid with a biotinylated secondary antibody, rinsed again in TBS buffer, and then incubated with a streptavidin-peroxidase conjugate. Sections were then incubated with a substrate-chromagen mixture (AEC; Zymed Labs., Inc.), counterstained with hematoxylin, and coverslipped.

Electron microscopy (EM) studies. Agarose blocks containing the fibroblast colonies were harvested between days 10 and 14 , fixed overnight in $2 \%$ gluteraldehyde at $4{ }^{\circ} \mathrm{C}$, and then processed for transmission EM analysis.

Cytokine modulation of anchorage-independent growth. All soft agarose studies were performed as described above with the following modifications. Fibrotic, neonatal, and normal adult lung fibroblast lines were cultured in a $0.4 \%$ agarose top layer containing either PDGF ( 5 $\mathrm{ng} / \mathrm{ml})$, TGF- $\beta(100 \mathrm{pg} / \mathrm{ml})$, or dexamethasone $\left(10^{-6} \mathrm{M}\right)$ in the presence of $20 \%$ human serum. The cultures were then incubated at $37^{\circ} \mathrm{C} /$ $5 \% \mathrm{CO}_{2}$ and colony growth (diameter, $\geq 45 \mu \mathrm{m}$ ) was assessed $10-14 \mathrm{~d}$ after plating. All experiments were performed in duplicate.

\section{Results}

Fibrotic adult and normal neonatal lung fibroblast cell lines exhibit colony formation under anchorage-independent conditions. The number of colonies appearing 10-14 d after plating is presented in Table I. Examination of three fibroblast cell lines derived from areas of fibrotic lung tissue reveals that IPF fibroblasts readily form colonies under soft agarose growth conditions. In contrast, fibroblast lines derived from normal adult lung tissue do not exhibit the capacity to grow under anchorage-independent conditions. As a group, IPF fibroblasts form colonies with a frequency of $0.54 \%$ compared with 
Table I. Lung Cell Line Colonies

\begin{tabular}{lcccc}
\hline $\begin{array}{c}\text { Tissue } \\
\text { derivation }\end{array}$ & $\begin{array}{c}\text { Cell } \\
\text { line }\end{array}$ & Exp. & $\begin{array}{c}\text { No. of } \\
\text { colonies* }\end{array}$ & $\begin{array}{c}\text { Percent } \\
\text { CFU }^{*}\end{array}$ \\
\hline Fibrotic & 1 & 1 & $85.75 \pm 2.87$ & \\
& 2 & 1 & $93.75 \pm 3.10$ & \\
& & 2 & $88.00 \pm 13.95$ & \\
& 3 & 1 & $89.00 \pm 5.48$ & \\
Normal & 1 & 2 & $79.50 \pm 11.45$ & \\
& & 2 & $0.50 \pm 0.58$ & \\
& 2 & 1 & $0.25 \pm 0.50$ & \\
& & 2 & $0.00 \pm 0.82$ & 0.003 \\
& 3 & 1 & $0.00 \pm 0.00$ & \\
& & 2 & $0.00 \pm 0.00$ & \\
Neonatal & 4 & 1 & $1.25 \pm 0.96$ & \\
& & 2 & $1.00 \pm 1.41$ & \\
& 1 & 1 & $66.00 \pm 2.16$ & \\
Tumor & & 2 & $63.75 \pm 5.50$ & 0.43 \\
(HT-1080) & & 1 & $65.25 \pm 1.89$ & \\
\hline & & 2 & $71.00 \pm 2.31$ & \\
& & 1 & $193.75 \pm 6.65$ & 1.1 \\
& & 2 & $157.75 \pm 20.15$ & \\
\hline
\end{tabular}

Data are number of colonies per well in semisolid agar suspension with a diameter $>45 \mu \mathrm{m}$ from $1.5 \times 10^{4}$ cells. ${ }^{*}$ Values represent the mean \pm SD of the number of colonies per well in eight wells. All statistical analysis was performed with the aid of Minitab Data Analysis Software, Release $7.1^{\circledR}$ (1989; Minitab, Inc., State College, PA). ${ }^{\ddagger}$ Percent CFU was calculated by averaging the number of colonies obtained by each group (fibrotic, normal, etc.) and dividing by the number of input cells per well.

$0.003 \%$ observed for normal adult lung fibroblasts. Our previous studies indicated that fibroblast lines derived from normal neonatal lung tissue proliferated faster than those from normal adult lung, and we examined whether these neonatal lines would also show abnormal growth in the assay. We show here that neonatal lung primary fibroblast lines exhibit colony formation under soft agarose growth conditions with a frequency of $0.43 \%$, only slightly less frequent than the IPF lines.

For comparison with a fully transformed cell line, we also examined the pattern of anchorage-independent growth for the tumorigenic cell line HT-1080 (human fibrosarcoma cell line). HT-1080 yielded twice the number of colony-forming units ( $1.1 \%$ frequency) as compared with IPF lung fibroblast-derived colonies.

Morphological examination reveals a fibroblast-like nature to the colonies. Histological and EM examination of lung colonies was performed to determine morphological characteristics associated with colony growth. Over 30 colonies from each cell line were examined in detail. Fig. 1, $A$ and $B$, illustrate a typical lung colony from a fibrotic cell line showing an inner multicellular centre surrounded by an extracellular granular type material, which stains intensely with hematoxylin and appears to be deposited into the agarose gel. Closer examination of each cell within the colony framework reveals the presence of large rounded nuclei, dispersed nuclear chromatin, and prominent nucleoli, all within an extensive cytoplasm.

The ultrastructural appearance of the colonies examined by EM analysis supports a fibroblast-like morphology for these cells (Fig. 2). The absence of intercellular junctions, basal lamina, or Weibel-Palade bodies all serve to exclude an epithelial or endothelial lineage to these cells (26). There does not appear to be myofibrils present, suggesting these are not myofibroblasts. Interestingly, EM analysis also demonstrates a number of ultrastructural features characteristic of proliferating fibroblasts, including the presence of rounded nuclei, prominent nucleoli, numerous cellular organelles with abundant elongated mitochondria, cytoplasmic processes, and the apparent absence of collagen fibres.

Immunohistochemical studies of fibrotic and neonatal lung colonies. Immunohistochemical studies were carried out on fixed colony sections derived from both fibrotic and neonatal lung lines in order to investigate the distribution of a variety of different cytoskeletal and ECM proteins characteristic of fibroblasts. Immunostaining of intermediate filaments and various actin isoforms reveals that both the fibrotic and neonatal lung colonies ( $>30$ examined) exhibit similar staining patterns for cytoskeletal and ECM proteins. Colonies stained positive for vimentin, laminin, fibronectin, and fibronectin receptor, exhibiting both cellular and extracellular localizations (Fig. 1, $C-F)$. The colonies also demonstrated intense cytoplasmic and extracellular staining for $\beta$-actin and tropomyosin, indicating the structural organization of these proteins into stress fibers (27). Colonies stained negative for $\alpha$ smooth muscle cell actin, desmin, keratin, Factor VIII, and tenascin.

Control sections of adult human normal lung fibroblasts suspended, but not cultured, in agarose were similarly investigated by immunoperoxidase staining for expression of intermediate filaments and ECM organization. Normal lung fibroblasts stained positive for vimentin, laminin, $\beta$-actin, fibronectin, and fibronectin receptor, and stained negative for desmin, keratin, tenascin, and $\alpha$ smooth muscle cell actin.

Colony expansion and replating. To assess whether the capacity to form colonies develops as a result of the assay conditions or is an intrinsic property of a cell population, single colonies with a diameter $>45 \mu \mathrm{m}$ were picked from low melt agarose. The cells were expanded to $5 \times 10^{6}$ (representing a further 22 population doublings from a single clone) and either reintroduced into the soft agarose culture system or carried for a further 2 passages and then reexamined in the colony assay. The ability of individual expanded clones to again form colonies was demonstrated, however, in general, the percentage of colony-forming units was observed to decrease with successive passage, from $0.38 \%$ with the parent line to $0.08 \%$ at a further two passages of the expanded colony (Table II).

Effect of PDGF, TGF- $\beta$, and corticosteroid on growth in soft agarose. To examine possible mediators of colony formation in the soft agarose conditions, PDGF, TGF- $\beta$, and DEX were tested for their ability to modulate anchorage-independent growth. Fig. 3 illustrates that the addition of PDGF or DEX greatly enhances soft agarose colony growth of fibroblasts derived from fibrotic lung tissue, but has little effect on neonatal fibroblast colony growth. TGF- $\beta$, in contrast, acts by partially inhibiting the ability of both fibrotic and neonatal lung fibroblasts to form colonies. On the contrary, the addition of PDGF, TGF- $\beta$, or corticosteroid did not induce any colony growth by normal adult lung fibroblasts.

\section{Discussion}

We have previously shown that cell lines isolated from fibrotic adult lung tissues compared with normal lung lines exhibit 

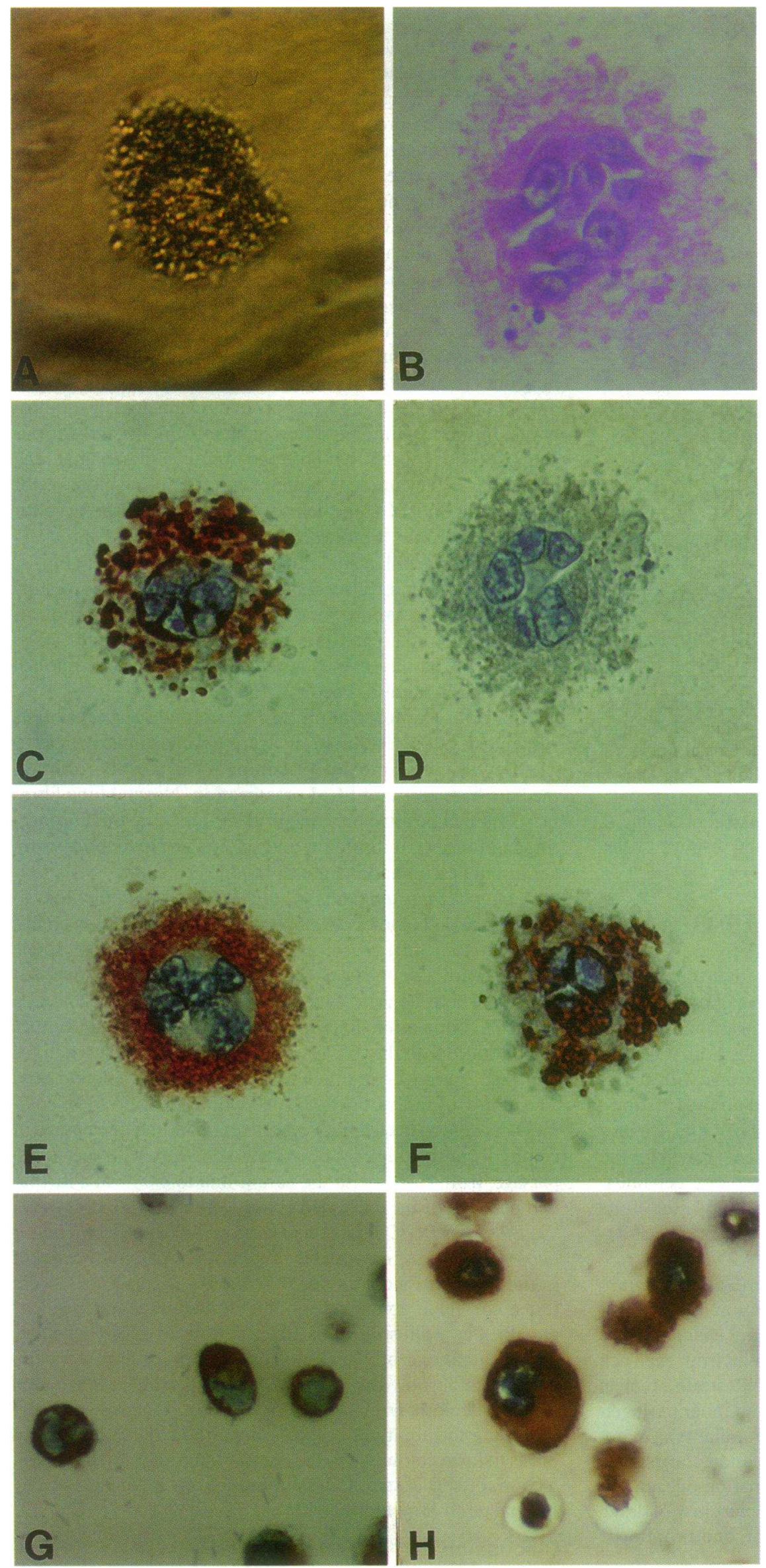

Figure 1. Morphology of anchorage-independent colony growth. $(A)$ Appearance of fibrotic lung fibroblast-derived cell line cultured in soft agarose assay (day 14) as visualized under an inverted light microscope (original, $\times 63$ ). (B) Representative hematoxylin and eosin-stained section of an adult fibrotic lung-derived colony (original, $\times 63)$. $(C-H)$ Immunoperoxidase staining of AcA-fixed agarose sections containing lung colonies. Staining of adult fibrotic lung colonies for vimentin showing both an intracellular and extracellular deposition and the normal mouse serum control $(C-D)$. Staining of adult fibrotic lung colony for the fibronectin $(F)$ and its receptor $(E)$. Immunoperoxidase staining of AcA-fixed normal adult lung fibroblasts in agarose stained for vimentin and the fibronectin receptor $(G-H)$ (original, $\times 64)$. 

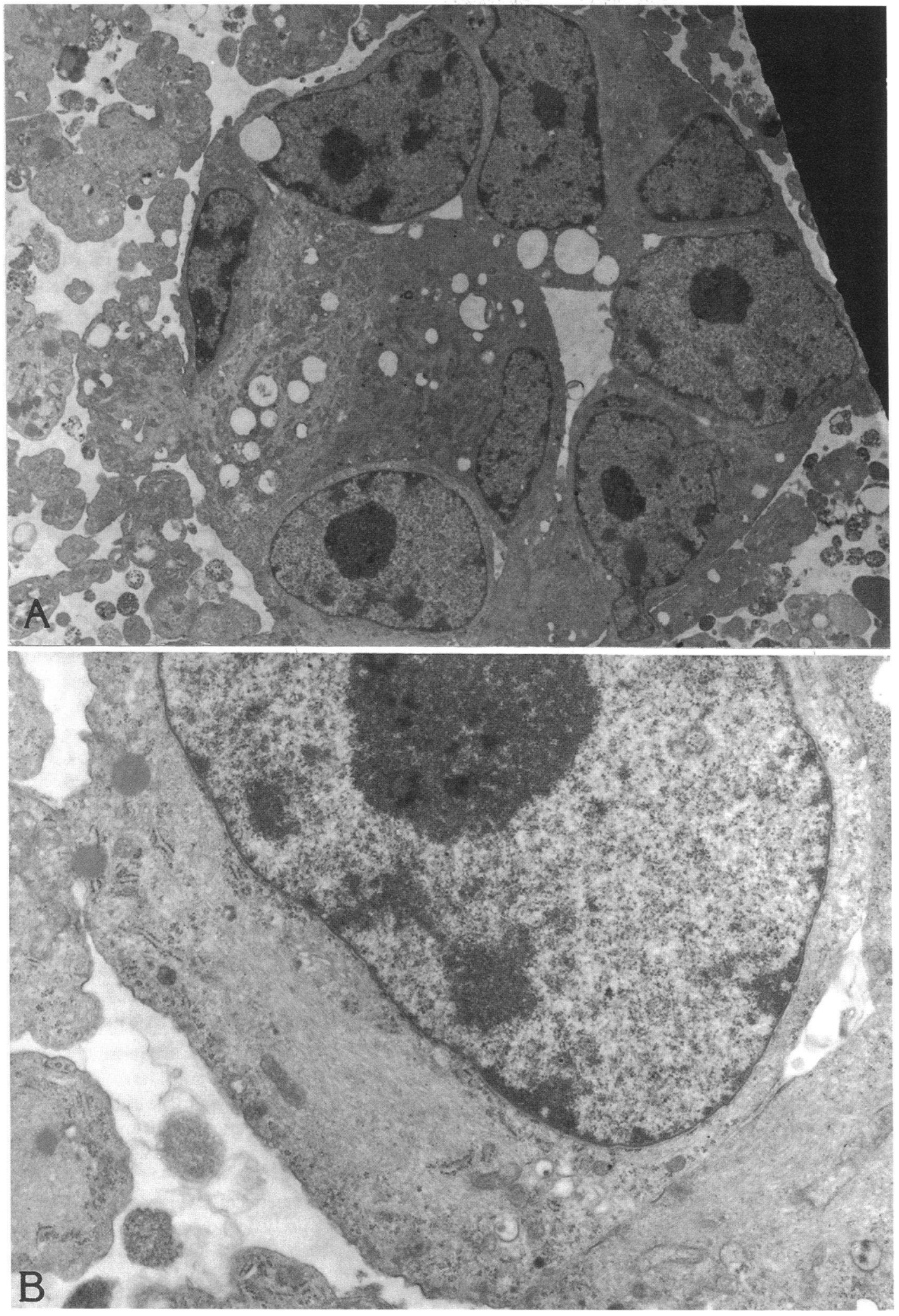

Figure 2. EM analysis. EM examination of a fibrotic lung-derived colony. $(A)$ A micrograph of one fibrotic lung-derived colony showing the multicellular nature of the colony (original, $\times 1,900)$. (B) EM of a single cell within the colony. Note the large round nucleus, prominent nucleoli, and dispersed heterochromatin (original, $\times 9,100)$.

faster proliferative characteristics (16). In this study, using a soft agarose culture system, we have shown that fibroblasts derived from fibrotic lung tissue (IPF) exhibit colony growth under anchorage-independent conditions whereas fibroblasts derived from normal adult lung tissue do not. This is further evidence of heterogeneity within lung fibroblast populations and between healthy and diseased (IPF) fibroblasts. We have also previously shown that primary lines of neonatal lung fibroblasts proliferate faster than control fibroblast lines (17), and demonstrate here that neonatal lung cell lines also form colonies under anchorage-independent growth conditions (Table I). These results suggest that cells exhibiting the ability to grow under anchorage-independent conditions in fibrotic lung tissue may bear some resemblance to the differentiating embryonic 
Table II. Results of Replating Experiment

\begin{tabular}{lclc}
\hline \multicolumn{1}{c}{ Cell line } & Exp. & No. of colonies* & $\begin{array}{c}\text { Percent } \\
\text { CFU }^{*}\end{array}$ \\
\hline Fibrotic & 1 & $85.75 \pm 2.87$ & 0.58 \\
Cell line no. 1 & 2 & $93.75 \pm 3.10$ & \\
Fibrotic & 1 & $55.50 \pm 8.43$ & 0.38 \\
Passage 4 & 2 & $62.25 \pm 16.11$ & \\
Fibrotic & 1 & $12.75 \pm 8.42$ & 0.08 \\
Passage 6 & 2 & $10.50 \pm 5.57$ & \\
\end{tabular}

Single colonies from a fibrotic cell line were picked from low-melt agarose, expanded in culture, and reintroduced into the soft agarose culture system. Colonies with a diameter $>45 \mu \mathrm{m}$ were counted and the results for one clone (no. 6) and its parent cell line depicted.

* Values represent the mean \pm SD of the number of colonies per well in eight wells. ${ }^{\ddagger}$ Percent CFU was calculated as per Table I.

fibroblast, a finding not at all surprising when one considers the sudden recruitment of actively dividing fibroblasts during wound healing and repair. Moreover, the ability of these cells to grow under anchorage-independent conditions, a characteristic generally associated with a transformed phenotype, suggests an aggressive nature to these cells consistent with the fibroproliferative nature of fibrosing disease. We cannot, however, relate proliferative capacity with anchorage-independent growth as we have no evidence directly linking the two characteristics.

The ability to form colonies under soft agarose growth assay conditions has also been documented for synoviocytes isolated from knee joints of patients with rheumatoid arthritis and from experimental animal models of rheumatoid arthritis, another chronic inflammatory connective tissue disease (24). It was proposed by these authors that these synoviocytes exhibit a "transformed-like" phenotype, although no evidence for transformation was demonstrated. Thus, long-lived structural cells may play a critical role in the pathogenesis of fibrosis, after repeated episodes of inflammation and repair, by means of the emergence of a group of phenotypically altered cells that pos-

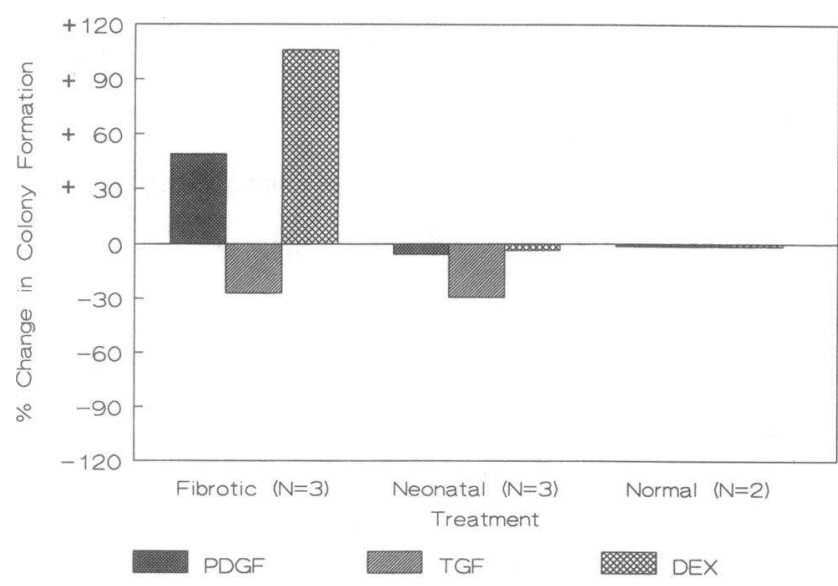

Figure 3. Modulation of growth in soft agarose by PDGF, TGF- $\beta$, and corticosteroid. Human fibroblast cell lines derived from fibrotic, neonatal, and normal adult lung tissue were cultured under soft agarose growth conditions in the presence of PDGF $(5 \mathrm{ng} / \mathrm{ml})$, TGF- $\beta$ ( 100 $\mathrm{pg} / \mathrm{ml})$, of $\operatorname{DEX}\left(10^{-6} \mathrm{M}\right)$ as described in Methods. sess characteristics pivotal to the continued presence of inflammation.

HT-1080 fibrosarcoma cells are transformed tumor cells presumably having clonal identity. Thus, all cells should be capable of growing as a colony in soft agarose. However, in the assay as performed, for HT-1080 cells, the colony-forming unit frequency is only $1.1 \%$ of plated cells, suggesting the assay may underestimate the potential for colony formation. The estimated frequency of colony-forming units for IPF lines $(0.54 \%)$ may also underestimate this capacity.

The ability to exhibit anchorage-independent growth appears to be intrinsic to cells in the original population since colonies that are picked and expanded can again form colonies, although at a reduced rate when compared with the parent line (Table II). The fact that we observe a reduction after passage in culture of the colonies is consistent with previous reports (28, 29) demonstrating a similar decrease in proliferative capacity as clones of normal dermal fibroblasts are passaged. Moreover, a decrease in the colony-forming capacity of late passage synoviocytes as compared with early passage synoviocytes has also been documented (24). These data suggest a progressive shift in the proportion of immature fibroblasts, possibly those that proliferate faster, within the population capable of forming colonies to a more differentiated fibroblast that loses its ability to form colonies.

To better characterize the nature of the fibrotic fibroblast phenotype, we examined both fibrotic and neonatal lung colonies using conventional histological, immunohistological, and ultrastructural analysis. Upon histological examination, a dense granular-type material was seen to be deposited within the agarose directly surrounding the colony (Fig. $1 \mathrm{~B}$ ). It is possible that this extracellular material may function, at least in part, to provide a source of stability and support to the growing colony. Both fibrotic and neonatal lung-derived colonies retained intermediate filament phenotypes consistent with fibroblast morphology as described by others (the presence of vimentin, and the absence of keratin and desmin) $(30,31)$. The immunolocalization of vimentin was found to be both intracellular and extracellular, indicating that this protein is being released into the matrix surrounding the colony, as a result of cell lysis (32).

In considering the source and nature of the cell that exhibits colony-forming activity in the primary line, two possible candidate cells in pulmonary tissue should be considered. The presence of a fibroblast-like cell in granulation tissue during healing has been described that shares structural and functional features of both smooth muscle cells and fibroblasts and that exhibits immunostaining to $\alpha$-SMC actin $(33,34)$. Since myofibroblasts share immunohistochemical features with those of fibroblasts, that is, vimentin positive and desmin negative, and since myofibroblasts have been described and are implicated in the pathogenesis of IPF (35) and bronchial asthma (36), we examined our lung colonies for $\alpha$-SMC actin expression. Neither the fibrotic-derived lung fibroblast colonies nor the neonatal-derived lung fibroblast colonies stained positive for $\alpha$-SMC actin, suggesting the myofibroblast is not a component of the colony-forming unit.

A second cell that has possible relevance is the pericyte, which has morphology similar to the fibroblast and may provide a precursor population for newly differentiated fibroblasts and/or smooth muscle cells during wound repair $(37,38)$. Pericytes express an important matrix protein, tenascin, that is 
known to be expressed during embryonic development, during tissue growth and reorganization, and in the stroma of some malignant tumors occurring in adulthood $(39,40)$. No tenascin-positive staining was observed in either the fibrotic or neonatal lung colonies.

The finding that colonies are negative for both $\alpha$-SMC actin and tenascin would seem to rule out both the pericyte or myofibroblast as being present in the colony $(39,41)$, but does not necessarily rule out their role as precursors to the colony-forming cell. These aspects are currently under investigation in our laboratory.

Examination of lung colonies for the expression of other extracellular matrix proteins demonstrates that both fibrotic and neonatal lung colonies were positive for laminin expression (with most of the antibody localized in the cytoplasm) and that both types of colonies appear to synthesize and secrete large quantities of fibronectin (Fig. $1 F$ ). Moreover, intense extracellular immunostaining was also demonstrated for the fibronectin receptor, suggesting the receptor is continually being expressed and removed from the cell surface, however, in the case of the colonies, this is held in the immediate area by the agarose matrix (Fig. $1 E$ ). Normal lung fibroblasts also exhibited immunostaining to laminin, fibronectin, and the fibronectin receptor. In the case of the fibronectin receptor, localization was specific to the cytoplasm with no evidence of extracellular deposition into the surrounding agarose, however, these cells were not cultured in the agarose for any time. In the context of wound healing and repair, an increase in expression of the fibronectin receptor could promote the migration of selected clones of fibroblasts into areas of active injury, where under the appropriate signals they may continue to proliferate and lay down fibrous material $(42,43)$. Fibronectin receptor expression may also function to allow the growing colony to remain anchored to the extracellular fibronectin it has deposited.

To better understand the mechanisms surrounding the soft agarose growth response of the various lung fibroblast types (i.e., fibrotic, etc.), and determine susceptibility to cytokine exposure, PDGF, TGF- $\beta$, and DEX were tested for their ability to modulate colony formation. The addition of PDGF, which is a known stimulator of fibroblast proliferation, greatly enhanced $(\sim 50 \%)$ the number of colonies formed by fibrotic lung fibroblasts, but showed little effect on neonatal colony formation. TGF- $\beta$, which is known to mediate the transformation of fibroblasts, was found to partially inhibit the colonyforming abilities of both fibrotic and neonatal lung fibroblast cell lines. Similar findings have also been documented for rheumatoid arthritis synoviocytes, with PDGF simulating and TGF- $\beta$ inhibiting colony formation $(24,44)$. The finding that PDGF and TGF- $\beta$ are not able to induce colony formation in any of the normal adult lung fibroblast cell lines implies that the mechanisms surrounding colony formation in soft agarose are not simply due to susceptibility to growth factors present in the culture media, but likely the result of phenotypic differences inherent to the initial fibroblast subpopulation itself, as PDGF induces fibroblast proliferation under normal culture conditions (adherence) in these same cells (data not shown).

This study also demonstrates that glucocorticoid has a marked effect on fibrotic lung fibroblast colony formation, with DEX enhancing colony formation by nearly $100 \%$. In contrast and similar to response to PDGF, DEX was shown to have little effect on neonatal lung fibroblast colonies, and does not induce colony formation by normal adult lung fibroblasts.
The observation that treatment with steroid actually enhances the numbers of colony-forming cells in the fibrotic lung fibroblast population raises questions as to the exact role antiinflammatory drugs play in the treatment of fibrosing disease.

Our data demonstrate that fibroblasts obtained from chronically inflamed fibrotic lung tissue behave differently under anchorage-independent growth conditions than fibroblasts obtained from normal lung tissue. Further, this behavior is present in fibroblasts obtained from neonatal lung tissue. The similar behavior seen in fibrotic and neonatal cell lines suggest newly differentiated cells with aggressive growth characteristics populate fibrotic tissue contributing to the altered growth and matrix deposition. Whether these colony-forming cells are direct contributors to the process is as yet unclear, but clearly shows a phenotypic difference between normal and fibrotic lines in growth and cytokine response characteristics.

Lafyatis et al. (24) have previously shown that human synovial fibroblasts maintain colony growth in soft agarose. Synovial cells have been shown to possess a variety of markers indicative of an "aggressive phenotype," including PDGF, FGF, and TGF- $\beta$ expression $(45,46)$. Moreover, the cytoskeletal and ECM components that we have observed in the lung colonies are also found in normal lung fibroblast cell lines. This suggests that the ability to grow in soft agarose may be due to a secreted product(s) or other membrane-bound protein important in growth and differentiation, and not expressed by quiescent normal lung fibroblasts. The future direction in characterizing the phenotype of the soft agarose-growing lung fibroblast may lie in the analysis of steady state levels of growth factors, cytokines, and their receptors known to be important in cell growth and differentiation. Moreover, further phenotyping of these lung colonies may help to address the role of subpopulations of fibroblasts in the propagation of chronic tissue inflammation.

\section{Acknowledgments}

This work was supported by Heart and Stroke Foundation of Ontario (HSFO) and the Medical Research Council of Canada and by Astra Pharma Canada. Dr. C. D. Richards is an Ontario Ministry of Health Scholar. Dr. T. Podor is an HSFO Scholar.

\section{References}

1. Basset, F., V. J. Ferrans, P. Soler, T. Takemura, Y. Fukuda, and R. G. Crystal. 1986. Intraluminal fibrosis in interstitial lung disorders. Am. J. Pathol. 122:443-461.

2. Katzenstein, A. L. 1985. Pathogenesis of "fibrosis" in interstitial pneumonia: an electron microscopy study. Hum. Pathol. 16:1015-1024.

3. Madri, J. A., and H. Furthmayr. 1980. Collagen polymorphism in the lung: an immunohistochemical study of pulmonary fibrosis. Hum. Pathol. 11:353366.

4. Kavlinsky, J. B. 1982. Glycosaminoglycans in emphysematous and fibrotic hamster lungs. Am. Rev. Respir. Dis. 125:85-86.

5. Starcher, B. C., C. Kuhn, and J. E. Overton. 1978. Increased elastin and collagen content of the lungs of hamster receiving an intratracheal injection of bleomycin. Am. Rev. Respir. Dis. 117:299-305.

6. Bateman, E. D., M. Turner-Warwick, and B. C. Adelmann-Grill. 1981. Immunohistochemical study of collagen types in human foetal lung and fibrotic lung disease. Thorax. 36:645-653. 329.

7. Dunnill, M. S. 1990. Pulmonary Fibrosis. Histopathology (Oxf.). 16:321-

8. Kuhn, C., J. Boldt, T. E. King, E. Crouch, T. Vartio, and J. A. McDonald. 1989. An immunohistochemical study of architectural remodeling and connective tissue synthesis in pulmonary fibrosis. Am. Rev. Respir. Dis. 140:1693-1703.

9. Crystal, R. G., P. B. Bitterman, S. I. Rennard, A. J. Hance, and B. A. Keogh. 1984. Interstitial lung diseases of unknown cause: disorders characterized by chronic inflammation of the lower respiratory tract. N. Engl. J. Med. 310:154166. 
10. Jordana, M., G. Cox, T. Ohtoshi, X. Zhou, J. Dolovich, J. Denburg, and J. Gauldie. 1991. The 'TDR' concept in chronic airways inflammation: tissue driven response. In Clinical Impact of the Monitoring of Allergic Inflammation P. Matson, S. Ahlstedt, P. Venge, and J. Thorell, editors. Academic Press Limited, London. 33-46.

11. Gauldie, J., M. Jordana, G. Cox, T. Ohtoshi, J. Dolovich, and J. Denburg. 1992. Fibroblasts and other structural cells in airway inflammation. Am. Rev Respir. Dis. 145:S14-S17.

12. Uitto, J., E. A. Bauer, and A. Z. Eisen. 1979. Increased biosynthesis of triple-helical type I and type III procollagens associated with unaltered expression of collagenase by skin fibroblasts in culture. J. Clin. Invest. 64:921-930.

13. Raghu, G., Y. Chen, V. Rusch, and P. S. Rabinovitch. 1988. Differential proliferation of fibroblasts cultured from normal and fibrotic human lungs. Am. Rev. Respir. Dis. 138:703-708.

14. Bordin, S., R. C. Page, and A. S. Narayanan. 1984. Heterogeneity of normal human diploid fibroblasts: isolation and characterization of one phenotype. Science (Wash. DC). 223:171-173.

15. Derdak, S., D. P. Penney, P. Keng, M. E. Felch, D. Brown, and R. P Phipps. 1992. Differential collagen and fibronectin production by Thy $1^{+}$and Thy $1^{-}$lung fibroblast subpopulations. Am. J. Physiol. 263:L283-L290.

16. Jordana, M., J. Schulman, C. McSharry, L. B. Irving, M. T. Newhouse, G Jordana, and J. Gauldie. 1988. Heterogeneous proliferative characteristics of human adult lung fibroblast lines and clonally derived fibroblasts from control and fibrotic tissue. Am. Rev. Respir. Dis. 137:579-584.

17. Jordana, M., H. Kirpalani, and J. Gauldie. 1992. Heterogeneity of human lung fibroblast proliferation in relation to disease expression. In Pulmonary Fibroblast Heterogeneity. R. P. Phipps, editor. CRC Press, Boca Raton, Inc., FL. 229249.

18. Kelley J. 1992. Transforming growth factor- $\beta$. In Cytokines in the Lung. J. Kelley, editor. Marcel Dekker, Inc., New York. 101-138.

19. Fabisiak, J. P., and J. Kelley. 1992. Platelet-derived growth factor. In Cytokines in the Lung. J. Kelley, editor. Marcel Dekker, Inc., New York. 3-37.

20. Antoniades, H. N., M. A. Bravo, R. E. Avila, T. Galanopoulos, J. NevilleGolden, M. Maxwell, and M. Selman. 1990. Platelet-derived growth factor in idiopathic pulmonary fibrosis. J. Clin. Invest. 80:1055-1064.

21. Martinet, Y., W. N. Rom, G. R. Grotendorst, G. R. Martin, and R. G. Crystal. 1987. Exaggerated spontaneous release of platelet-derived growth factor by alveolar macrophages from patients with idiopathic pulmonary fibrosis. $N$. Engl. J. Med. 317:202-209.

22. Khalil, N., R. N. O'Connor, H. W. Unruh, P. W. Warren, K. C. Flanders, A. Kemp, O. H. Bereznay, and A. H. Greenberg. 1991. Increased production and immunohistochemical localization of transforming growth factor in idiopathic pulmonary fibrosis. Am. J. Respir. Cell Mol. Biol. 5:155-162.

23. Broekelmann, T. J., A. H. Limper, T. V. Colby, and J. A. McDonald. 1991. Transforming growth factor $\beta 1$ is present at sites of extracellular matrix gene expression in human pulmonary fibrosis. Proc. Natl. Acad. Sci. USA. 88:6642-6646.

24. Lafyatis, R., E. F. Remmers, A. B. Roberts, D. E. Yocum, M. B. Sporn, and R. L. Wilder. 1989. Anchorage-independent growth of synoviocytes from arthritic and normal joints: stimulation by Exogenous platelet-derived growth factor and inhibition by transforming growth factor-beta and retinoids. J. Clin. Invest. 83:1267-1276.

25. Hirte, H. W. 1993. A quantitative colony-forming bioassay for transforming growth factor- $\beta$ using a colorimetric endpoint. Proc. Am. Assoc. Cancer Res. 34:1429 (Abstr.).

26. Rhodin, Johannes A. G. 1974. Connective Tissue. In Histology, a Text and Atlas. Oxford University Press, London. 140-171, 348.

27. Goldman, R. D., E. Lazarides, R. Pollack, and K. Weber. 1975. The distribution of actin in non-muscle cells: the use of actin antibody in the localiza- tion of actin within the microfilament bundles of mouse 3T3 cells. Exp. Cell Res. 90:333-344.

28. Kirkwood, T. B. L., and R. Holliday. 1975. Commitment to Senescence: a Model for the finite and infinite growth of diploid and transformed human fibroblasts in culture. $J$. Theor. Biol. 53:481-496.

29. Jones, R. B., and J. R. Smith. 1982. A stochastic model of cellular senescence. II. Concordance with experimental data. J. Theor. Biol. 96:443-460.

30. Franke, W. W., B. Appelhans, E. Schmid, C. Freudenstein, M. Osborn, and K. Weber. 1979. Identification and characterization of epithelial cells in mammalian tissues by immunofluorescence microscopy using antibodies to prekeratin. Differentiation. 15:7-25.

31. Franke, W. W., C. Grund, C. Kuhn, B. W. Jackson, and K. Illmensee. 1982. Formation of cytoskeletal elements during mouse embryogenesis III. Primary mesenchymal cells and the first appearance of vimentin filaments. Differentiation. 23:43-59.

32. Podor, T. J., J. I. Weitz, J. Hirsh, D. Seiffert, and D. J. Luskutoff. 1994. Vitronectin-mediated binding of type 1 plasminogen activator inhibitor to vimentin intermediate filaments in damaged endothelial cells: potential mechanism for regulating plasmin generation during the inflammatory process. J. Clin. Invest. In press.

33. Darby, I., O. Skalli, and G. Gabbiani. 1990. $\alpha$-smooth muscle actin is transiently expressed by myofibroblasts during experimental wound healing. Lab. Invest. 63:21-29.

34. Gabbiani, G., G. B. Ryan, and G. Majno. 1971. Presence of modified fibroblasts in granulation tissue and their possible role in wound contraction. Experientia (Basel). 27:549-550.

35. Kuhn, C., and J. A. McDonald. 1991. The roles of the myofibroblast in idiopathic pulmonary fibrosis: ultrastructural and immunohistochemical features of sites of active extracellular matrix synthesis. Am. J. Pathol. 138:12571265 .

36. Roche, W. R., R. Beasley, J. H. Williams, and S. T. Holgate. 1989. Subepithelial fibrosis in the bronchi of asthmatics. Lancet. ii:520-524.

37. Sims, D. E. 1991. Recent advances in pericyte biology: implications for health and disease. Can. J. Cardiol. 7:431-443.

38. Shepro, D., and N. M. L. Morel. 1993. Pericyte physiology. FASEB (Fed. Am. Soc. Exp. Biol.) J. 7:1031-1038.

39. Mackie, E. J., W. Halfter, and D. Liverani. 1988. Induction of tenascin in healing wounds. J. Cell Biol. 107:2757-2767.

40. Chiquet-Ehrismann, R., E. J. Mackie, C. A. Pearson, and T. Sakakura. 1986. Tenascin: an extracellular matrix protein involved in tissue interactions during fetal development and oncogenesis. Cell. 47:131-139.

41. Skalli, O., M. F. Pelte, M. C. Peclet, G. Gabbiani, P. Gugliotta, G. Bussolati, M. Ravazzola, and L. Orci. 1989. $\alpha$-smooth muscle actin, a differentiation marker of smooth muscle cells, is present in microfilamentous bundles of pericytes. J. Histochem. Cytochem. 37:315-321.

42. Clark, A. F. 1990. Fibronectin matrix deposition and fibronectin receptor expression in healing and normal skin. J. Invest. Dermatol. 94:128S-134S.

43. Grinnell, F., K. Toda, and A. Takashima. 1987. Activation of keratinocyte fibronectin receptor function during cutaneous wound healing. J. Cell Sci. Suppl. 8:199-209.

44. Wilder, R. L., R. Lafyatis, A. B. Roberts, J. P. Case, G. K. Kumkumian, H. Sano, M. B. Sporn, and E. F. Remmers. 1990. Transforming growth factor- $\beta$ in Rheumatoid Arthritis. Ann. NY Acad. Sci. 593:197-207.

45. Goddard, D. H. 1992. Regulation of synovial cell growth by polypeptide growth factors. DNA Cell Biol. 11:259-263

46. Remmers, E. F., J. Sano, R. Lafyatis, J. P. Case, G. K. Kumkumian, T. Hla, T. Maciag, and R. L. Wilder. 1991. Production of platelet derived growth factor $\beta$ chain (PDGF-B/c-sis) mRNA and immunoreactive PDFG B-like polypeptide by rheumatoid synovium: coexpression with heparin binding acidic fibroblast growth factor-1. J. Rheumatol. 18:7-13. 